\title{
The Evolution of Consciousness
}

\author{
Bradley Y. Bartholomew \\ Independent Researcher, France
}

Copyright $(2018$ by authors, all rights reserved. Authors agree that this article remains permanently open access under the terms of the Creative Commons Attribution License 4.0 International License

\begin{abstract}
This paper presents a new and positive theory of evolution, as distinct from instancing certain unique features of the phenotype of whatever species, and asking the question 'How could this come about by natural selection of random genetic mutations'. Essentially this paper starts with the premise that intelligence and consciousness comes from the DNA, and that therefore these particular features of life must actually be embedded in the DNA. Once this premise is accepted then not only does the orthodox Neo-Darwinism as 'natural selection through random genetic mutations' appear an over-simplified, if not facile, explanation for the immense complexity and diversity to be found in Nature (which contrary to popular belief actually incudes human civilization as well), but also opens up the possibility that there really could be Intelligent Design coming from within the DNA itself. Erwin Schrödinger's theory of quantum biology that genetic mutations occur as discreet jumps according to the principles of quantum mechanics is also presented and explained.
\end{abstract}

Keywords New Synthesis, Mendel, Nanotechnology, Quantum Biology, Microtubules, Electromagnetism, Electronics

\section{Introduction}

Since Darwin penned On the Origin of the Species in 1859 , there has been a veritable deluge of publications supporting it, or highlighting some aspect of it, or further honing some nuance of it. In a very real sense the scientific community has adopted Neo-Darwinism as the ultimate explanation of life. When Darwin developed his theory, of course, relatively little was known of the mechanisms of genetics. The re-discovery, in the early twentieth century, of Mendel's work in inheritance, and the eventual development of the immense body of knowledge known as "genetics," seemed on the one hand to afford Darwinism a solid "scientific" foundation, while on the other hand throwing into doubt much of the traditional "adaption to the habitat," "struggle for survival," "survival of the fittest," "hunter-gatherer," and "natural selection" elements that provided grist for the Darwinian mill. Thus began the era of Neo-Darwinism, which attempts to effect a synthesis of the many strands of traditional Darwinism with the genetics revolution, of "hunter-gatherer adaptation to the environment" with the "natural selection of the random mutation of genes." The problem is that, the more that is known about genetic processes, the less clear it is that the differentiation of the millions of species that live or have lived on this planet has occurred through the natural selection of randomly mutated genes. Two very recent cases illustrate the problem. It is known that Homo sapiens crossbred with a hominin species called the Denisovans. Denisovan DNA has shown up in the genotype of the Melanesian people of Papua New Guinea and in East Asians, especially Han Chinese, Chinese Dai and Japanese people. The problem is that although the phenotype of the Melanesians is more similar to the Denisovan phenotype than that of East Asians, their genotype is less similar; while on the reverse of the coin, the phenotype of the East Asians is less similar, and their genotype is more similar, to the Denisovans than are those of Melanesians [1]. Another very recent research paper has introduced us to the problem of "dark DNA" [2], while many aspects of the workings of the RNA also remain a mystery and evidence is emerging that "RNA interference" plays a positive role in heredity and, indeed, that RNA may act as a "second code" [3]. On top of all this, there is an ever-growing body of research on epigenetic factors that also seem to be implicated in heredity. The truth of the matter is that Neo-Darwinism as a theory rests on an increasingly tenuous footing.

\section{Neo-Darwinism or the "New Synthesis"}

The fact of evolution is not contentious; debate within the scientific community centers, rather, around how it happens. Even before Darwin, Lamarck had theorized that acquired characteristics could be passed down to offspring, but this was early in the nineteenth century, long before Mendel's theory of genetic inheritance suggested a mechanism for such processes. Also, Lamarck's theory 
involved a subjective or mental element in evolution, at odds with science's requirement for an objective, mechanistic explanation. Darwin's On the Origin of Species made a splash because it offered just such an explanation - natural selection through survival of the fittest - although not only did it not explain the "origin" of any species, let alone Homo sapiens, but his principle thesis was primarily a Lamarckian explanation of how finches in the Galapagos Islands had acquired different physical characteristics as a result of the different foods available to them. Indeed, "natural selection through survival of the fittest" is essentially a Lamarckian mechanism as well. A cynical explanation for Darwin's success in the scientific community might eye the word "origin" in his title; here was the scientific alternative to the Book of Genesis, the Big Bang of biology.

The scientific community fastened on the phrase "natural selection" and ran with it, so much so that Darwin himself lamented the fact that he had been misrepresented. He wrote:

But as my conclusions have lately been much misrepresented, and it has been stated that I attribute the modification of species exclusively to natural selection, I may be permitted to remark that in the first edition of this work, and subsequently, I placed in a most conspicuous position - namely at the close of the Introduction - the following words: "I am convinced that natural selection has been the main but not the exclusive means of modification." [4]

And well he might complain; when Mendel was rediscovered at the beginning of the twentieth century, and the search began for the genetic material involved in inherited characteristics, his theory lost favor for a long while as evolutionary theorists, armed with an ever-increasing knowledge of genetics, criticized "natural selection" as not only too simplistic but as allowing mental elements to surreptitiously infiltrate the mechanistic story of evolution [5].

With the emergence of Neo-Darwinism, or the "New Synthesis," "natural selection" was back in vogue by the 1930s. Now, however, natural selection was theorized to be mediated through a dozen or more different factors - all or most subsequently found to be inadequate to explain the big picture. It is estimated that over 100,000 scientific papers have appeared discussing some aspect of the New Synthesis. Instead of a clear answer to this problem - the mechanism of natural selection -we have instead a huge corpus of forbiddingly technical literature on numerous peripheral or accessory topics: genetics, phylogenies, paleontology, hybrid theory, taxonomy, population dynamics, sociobiology, developmental biology, ecology, evolutionary psychology, game theory and more, all under the rubric of "evolution" [5].

Throughout this mass of theory, however, there is one unmistakable, essential thread in Neo-Darwinism: that the whole evolutionary tree of life has grown up as a result of "natural selection of random genetic mutations": we are here as a result of blind and mindless biochemical processes and, therefore, the tree of life can have no teleological aspect, no purpose or meaning. Indeed even the metaphor of a tree of life is misleading, suggesting as it may that some species are "higher" than others.

\section{The Diversity of Conscious Beings}

In the beginning - say, 3.8 billion years ago - inanimate substances such as water, carbon dioxide and ammonia "accumulated till the primitive oceans reached the consistency of hot dilute soup." Organic substances, such as sugars and amino acids, were synthesized. This led to the appearance of a single living cell, the first reproducing thing [6]. This obviously is hypothetical; the words "primordial soup" are just that, mere words, and we may notice here the first leap of faith - that from these sugars and amino acids emerged a primitive molecule akin to DNA or RNA, which contained the information needed not only how to build and sustain a living cell, but to establish a means by which that living cell could reproduce itself. Here, of course, the key word is "information," which in turn involves "intelligence" and, ultimately, "consciousness." This is the "New Synthesis" in a nutshell: in the beginning was the "primordial soup," from which emerged consciousness with a will to reproduce and the knowledge and means by which to do so.

Once we understand that in the beginning was a single cell with consciousness, the evolution of consciousness over the next 3.8 billion years, although astounding in terms of the diversity and complexity of conscious beings, is actually quite matter-of-fact in terms of the processes involved - so matter-of-fact indeed that scientists such as Richard Dawkins can glibly state:

All appearances to the contrary, the only watchmaker in nature is the blind forces of physics, albeit deployed in a very special way. A true watchmaker has foresight: he designs his cogs and springs, and plans their interconnections, with a future purpose in his mind's eye. Natural selection, the blind, unconscious, automatic process which Darwin discovered, and which we now know is the explanation for the existence and apparently purposeful form of all life, has no purpose in mind. It has no mind and no mind's eye. It does not plan for the future. It has no vision, no foresight, no sight at all. If it can be said to play the role of watchmaker in nature, it is the blind watchmaker. [7]

While this "orthodox" or "purely scientific" account of evolution is not further discussed in this paper, two key phrases in the above quotation - the "blind forces of physics" and "unconscious, automatic process" - will re-appear in the following sections. 
Much of this section follows a book titled Evolution Fact \& Fantasy: The Psychogenic Theory by Lawrence L. Horstman [5]. Horstman, whose main field of expertise is hematology, followed for forty years or more the Neo-Darwinian debate as a dedicated scientist skeptical of the orthodox theory. The theme of his book is that evolution must have contained a mental or intelligent component, a theory for which he coined the name "psychogenics." He starts his book with the following line: "Among the great unsolved problems in modern science, second only to that of consciousness, is that of biological evolution".

Psychogenics admits freely the existence of the evolutionary process. Where psychogenics takes issue with Neo-Darwinian orthodoxy is on the nature of that process. We have seen above that the New Synthesis encompasses a variety of theories, uneven in plausibility and in some cases even conflicting, but all seemingly distilled into the catchphrase, "natural selection through random genetic mutation." This orthodoxy, offers little in answer to the question of "how" the extraordinary variety and complexity to be seen everywhere in Nature could arise randomly, with no design or teleological purpose, from a single-celled organism. It reflects a dogmatic rejection on the part of mainstream science of any role for mind, intelligence, psychological factors and, above all, consciousness, in their account of evolution.

The psychogenic view - unlike the Neo-Darwinian orthodoxy, which actually serves to render consciousness mysterious - maintains that mental factors such as intelligence ultimately derive from DNA. This view can be represented as an Aristotelian First Principle: biology is the source of consciousness; DNA is the source of biology; ergo DNA is the source of consciousness. Another formulation of this first principle might be that DNA is consciousness. It is not just an inert chemical molecule, it is the principle of life, and it is capable of psychic communication with gifted persons. [8]Thus we arrive at the thesis of this article: that for the past 3.8 billion years there has been an evolution of consciousness, and it is this intelligence, which is in the DNA itself and is part and parcel of consciousness, that has masterminded or designed its own evolution. Of course drawing a link between DNA and intelligence invites the rebuttal that consciousness does not come ultimately, or at least exclusively, from DNA. Epigenetic factors and environmental factors also have a role in both intelligence and consciousness. DNA, in the context of this paper, is broadly drawn - epigenetic factors actually involve methylation of the DNA bases (also known as imprinted genes), a process that can be caused by environmental factors but the fact remains that these chemically modified bases actually become part of the DNA molecule itself. Thus the assertion that DNA is the source of intelligence and consciousness is intended to encompass epigenetic and environmental factors.

Psychogenics takes aim at the orthodox view that there is no place for notions of "progress" in evolution. Although we Homo sapiens can trace our ancestors back through a long line of earlier species - primates, reptiles, fish and ultimately, that single cell in the primordial soup - it is heterodox to suggest that this represents any form of progression. The orthodox deny progress for the simple reason that to admit progress is to admit that evolution is teleological - that is to say, that it has an aim, purpose or goal. Thus, in the face of the overwhelming evidence provided by the increasing complexity and capability of the many species that have evolved from a single-celled organism, the orthodox remain adamant that progress does not exist.

All these different species, however, currently existing or extinct, have had one essential feature in common, consciousness; and the denial of progress in evolution becomes even more surprising when one measures the consciousness of a hypothetical primordial, single-celled organism - a consciousness that could be little more than an urge to nourish and reproduce itself - against the consciousness of Homo sapiens, encompassing sensory perception, intelligence, will, emotions, memories and more, or even against the consciousness of the millions of other species, animal and vegetable, that have evolved between (or perhaps even beyond) these two extremes.

Even among adherents of the Neo-Darwinian orthodoxy, it is possible to find statements that support an evolution of consciousness, and even the notion of evolutionary progress. George Gaylord Simpson, a key figure in the New Synthesis, quotes with approval the following statement made by neurobiologist C. Judson Herrick: "Change in the direction of increase in the variety and range of adjustments of the organism to its environment," as Herrick puts it. ... is increased awareness and perception of the environment $\ldots$ and to develop appropriate adjustments. [5] no space between paragraph

Indeed, from this quotation we could attempt a definition of progress in evolutionary terms: Progress involves an increase in the variety and range of adjustments of the organism to its environment as well as an increased awareness, perception and consciousness of its environment leading to appropriate adjustments conducive to survival.

The physicist Erwin Schrödinger - whose theory about the quantum mechanical explanation for mutation we will encounter below - gave a series of lectures on Mind and Matter in which he defined consciousness [9]. Schrödinger stressed the fact that we perform many functions in life that may be difficult at first but, by virtue of repetition, become automatic to the point that we no longer think about it at all - that is to say, we are no longer conscious of doing them. Schrödinger stated: "Therefore consciousness is associated with those of its functions that adapt themselves by what we call experience to a changing environment ... I would summarize my general hypothesis thus: consciousness is associated with the learning of the living substance; its 
knowing how is unconscious" (emphasis in original). While the current paper is titled "The Evolution of Consciousness," the central topic in reality is the evolution of the unconscious mind for, as discussed later; it is the unconscious mind that acts as a mediator between consciousness and DNA.

Interestingly, Schrödinger advanced this definition of consciousness in support of his argument that ethics and social values have evolved in humankind; specifically, that the primitive and egoistic will of early humans has evolved throughout the history of human civilization in an apparently purposeful direction towards a more altruistic psychology and social behavior generally, and in particular stricter restraints on our sexual and aggressive urges. It is very clear that there has been an evolution of human social behaviors and values, but whether this evolution has been unconscious or conscious is a moot point.

Schrödinger takes a similar view to that of psychogenics in relation to the numerous variations in the form, abilities and behaviors, as well as the anatomies, of the various species that have appeared over the past 3.8 million years. And this view is essentially Lamarckianism - the inheritance of acquired characteristics whether consciously or unconsciously acquired.

There is a very true kernel in Lamarck's view, namely that there is an irrescindable causal connection between the functioning, the actually being put to profitable use of a character - an organ, any property or ability or bodily feature - and its being developed in the course of generations, and gradually improved for the purposes for which it is profitably used... The most remarkable feature among living beings is that they are divided into species which are, many of them, so incredibly specialized on quite particular, often tricky performances, on which especially they rely for survival ... It is difficult to believe that they have all resulted from Darwinian "accumulation by chance." Whether one wants it or not, one is taken by the impression of forces or tendencies away from "the plain and simple" in certain directions towards the complicated. The "plain and simple" seems to represent an unstable state of affairs. A departure from it provokes forces - so it seems - towards a further departure, and in the same direction. That would be difficult to understand if the development of a particular device, mechanism, organ, useful behavior, were produced by a long pearl string of chance events, independent of each other, such as one is used to thinking of in terms of Darwin's original conception. Actually, I believe, only the first small start "in a certain direction" has this structure. It produces itself circumstances which "hammer the plastic material" by selection - more and more systematically in the direction of the advantage gained at the outset. In metaphorical speech one might say: the species has found out in which direction its chance in life lies and pursues this path. [9]

It matters not whether "the species has found out in which direction its chance in life lies" unconsciously or consciously - ultimately it amounts regardless to an evolution of consciousness.

Schrödinger wrote the above long before the advent of the area of genetic research known as epigenetics, which has tended to offer an empirical vindication of Lamarckianism. It is now established that heritable changes acquired in the parent's experience (learned behaviors, adaptations to the environment, lifestyle, diet, substance abuse) can pass to offspring. Not only is Lamarck back in vogue, but Darwin himself thought that this would be possible. The DNA and other proteins in the chromosome become imprinted with chemical markers that can modify or even inhibit the expression of genes. In addition, there exists an array of specific enzymes, often acting in concert with other proteins, for adding and deleting these chemical markers. The bottom line is that the DNA itself has mechanisms that can cause alterations to the genome as a result of (consciously or unconsciously) acquired characteristics of the parents. The mere fact that the field of epigenetics exists gives the lie to the orthodox theory of natural selection of blind and random genetic mutations. Epigenetics gives the conscious and unconscious behaviors of the parents a very significant place in the story of evolution.

Darwinism, and later Neo-Darwinism, has been adopted as the orthodox theory of evolution for the simple reason that the whole thrust of the scientific method is to "objectify" the material world. Doing so required excluding the mind or soul - the Subject of Cognizance from the objective world picture. As a result, orthodox scientific theories have boxed themselves into a corner that is increasingly empirically untenable - not only in relation to evolutionary theory but also in relation to physics, where quantum mechanics has reintroduced the problem of consciousness with a vengeance. Schrödinger quotes C.G. Jung:

All science (Wissenschaft) however is a function of the soul, in which all knowledge is rooted. The soul is the greatest of all cosmic miracles, it is the conditio sine qua non of the world as an object. It is exceedingly astonishing that the Western world (apart from very rare exceptions) seems to have so little appreciation of this being so. The flood of external objects of cognizance has made the subject of all cognizance withdraw to the background, often to apparent non-existence.

No exposition of the evolution of consciousness would be complete without alluding to what Schrödinger calls "The Arithmetical Paradox: The Oneness of Mind." This problem, in a nutshell, is whether there is only one consciousness at work in the world, or whether, as certainly appears to be the case, there are trillions, if all the plants, 
insects, amoeba and algae - independent self-contained "monads" of consciousness that have the capacity to interact with each other but are in the last resort essentially distinct - are counted. The topic is universal, from the Hindu Upanishads assertion that there is only one cosmic consciousness in which all living creatures share, to the pre-Socratic philosopher Anaxagoras, who stated that there is only one cosmic mind, nous, from which all living creatures derive their individual soul. The question is answerable if all life is viewed as the evolution of consciousness, which is synonymous with the evolution of DNA. The DNA represents the single universal consciousness, and all individual consciousnesses are manifestations of it. This, by the way, is the conclusion that Schrödinger reaches as well.

But it is at the level of the individual organism that we find the true arithmetical paradox concerning the oneness of mind. Schrödinger ponders the question why every living cell in an organism (say a human being) contains a complete copy of the DNA for that organism. He quotes Sir Charles Sherrington:

The cell as a component of the body is not only a visibly demarcated unit but a unit-life centered on itself. It leads its own life ... The cell is a unit-life, and our life which in its turn is a unitary life consists utterly of the cell-lives. [9]

This paradox is particularly striking in relation to the brain, where the cortex is made up of a sheet of trillions of individual cells, each containing a complete copy of the human DNA in the nucleus, so each cell appears to be an autonomous unit; yet somehow this "commonwealth of cells" produces in us the impression of having a unified mind. "Matter and energy seem granular in structure, and so does 'life', but not so mind." Here we have one mind based ostensibly on many cell-lives; the only explanation Schrödinger could offer is that there must be a "sub-mind" associated with the individual cells that enables them to act perfectly in concert to produce a unified effect. He immediately dismisses this notion of a sub-mind in every living cell as an "absurd monstrosity." However, it is for every living cell, not just those of the brain, that this paradox arises. All living creatures consist of individual autonomous cells, whether one or millions or trillions, which act in concert to produce a unified effect. The solution to the paradox is that it is the DNA that acts as the "sub-mind." DNA is consciousness - at the cellular levelwhich explains why there must be a complete copy of the DNA in every living cell.

I conclude this section with Schrödinger's comments on the beginning of consciousness. After favorably noting Sherrington's observation that the human mind arrived comparatively recently, that is to say very late in the story of evolution, Schrödinger says:

It would seem queer, not to say ridiculous, to think that the contemplating, conscious mind that alone reflects the becoming of the world should have made its appearance only at some time in the course of this "becoming," should have appeared contingently, associated with a very special biological contraption which in itself quite obviously discharges the task of facilitating certain forms of life in maintaining themselves, thus favoring their preservation and propagation: forms of life that were late-comers and have been preceded by many others that maintained themselves without that particular contraption (a brain). Only a small fraction of them (if you count by species) have embarked on "getting themselves a brain." And before that happened, should it all have been a performance to empty stalls?

Evidence that all living cells have some basic consciousness is offered by the fact that decapitated flatworms turn away from light: deprived of eyes they can still "see" and deprived of a brain they can still display purposeful behavior [10]. One of the authors of the report is quoted as saying: "It's a fascinating coincidence that decapitation-regeneration experiments appear to copy chronologically, at least - what may have occurred in evolution."

\section{Consciousness Explained}

A recent article titled "Our Unconscious Soul: A re-look at Aristotle, Descartes and the Upanishads" proposes an explanation of consciousness [11]. Essentially, the Upanishads state that the Self is the creator of consciousness and that it is located in the part of the brain that operates during sleep. Other passages in the Upanishads that suggest that the Self is located in the embryonic brain at the beginning of life, and/or the parts of the brain that Western scientists have referred to as the reptilian complex (the basal ganglia and related structures), and that this is in fact the part of the brain that operates during sleep, both dreaming and deep sleep.

In his De Anima, Aristotle calls the soul "the first grade of actuality of a natural organized body" (412b4). Other passages in Aristotle's works suggest that the embryonic brain is the origin, soul, or first actuality of a living being. Indeed, Aristotle recognizes that sleep comes first in being and that wakefulness evolves later. He says in De Anima "for both sleeping and waking presuppose the existence of soul [consciousness], and of these waking corresponds to actual knowing, sleeping to knowledge possessed but not employed" (II,1, 412a23-26). Again, in Book IX of the Metaphysics Aristotle refers to the sleeping state of the soul as "potentiality" and the waking state as "actuality" (IX,6,1048b1-2). By five weeks after fertilization, the embryo cranium is bulging with midbrain that is firing spontaneously. It is true that Aristotle believed that during those very first weeks only the nutritive soul is present (Generation of Animals, II, 1, 735a15-23 and II,3, 
736a35-736b7) and that the embryo was in not a state of sleep per se "but as something resembling sleep, the sort of state that plants also are in, indeed at this stage animals are leading the life of a plant" (778b35-779a2). There can be no doubt, however, that he also believed that the true knowledge or the soul as potentiality was there as well. We may note here that plants do not have neurons, so his observation can be valid for the first five weeks only; once the neurons start to fire, there is something more going on than vegetative processes.

Thus, according to the Upanishads - and also Aristotle, by implication from the fact that he locates the soul in the embryonic brain - the soul is responsible for our dreaming state, and our brain is being programmed to achieve a state of wakefulness through our fetal dreams. This mirrors the theory of the French neurophysiologist, Michel Jouvet, that REM dreaming sleep is a genetic programming mechanism for the brain [12]. Thus, a complete explanation for consciousness will be that it emerges out of the sleeping state and it withdraws back into the sleeping state, and that the brain is programmed to achieve the state of consciousness via our fetal dreams.

It has also recently been determined that our long-term memories are stored in the putamen during deep sleep [13]. The putamen is also in the embryo brain region, along with the pineal gland that secretes melatonin during deep sleep $[14,15]$. Descartes famously located the soul in the pineal gland, and there is a high probability that the secretion of melatonin from the pineal gland is in fact an unconscious operation of the soul involved in storing our long-term memories.

Willam James, in his work The Varieties of Religious Experience [16], noted that:

[t]he subconscious self is nowadays a well accredited psychological entity; and I believe that in it we have exactly the mediating term required. Apart from all religious considerations, there is actually and literally more life in our total soul than we are at any time aware of. What Mr. Myers said in 1892 in his essay on the Subliminal Consciousness is as true as when it was first written: "Each of us is in reality an abiding psychical entity far more extensive than he knows an individuality which can never express itself completely through any corporeal manifestation. The Self manifests through the organism; but there is always some part of the Self unmanifested; and always, as it seems, some power of organic expression in abeyance or reserve." Let me then propose, as an hypothesis, that whatever it may be on the farther side, the "more" with which in religious experience we feel ourselves connected is on its hither side the subconscious continuation of our conscious life.

It turns out that the key to explaining consciousness is in fact to successfully explain the location and operations of our unconscious soul and, most importantly, to recognize that it is the part of the brain that operates during sleep. But having said that, once we know that our consciousness comes out of our sleeping state, then all we can ever say about life is that we appear to wake up, and when we do wake up we have a consistent set of memories of having woken up previously.

\section{Quantum Biology}

In this section, quantum mechanics as it applies to biology and biochemistry will only be discussed in the most general terms. Quantum mechanics is a mathematical theory that allows physicists to observe and predict what is happening at the atomic and subatomic level in matter. The core theory is Schrödinger's wave equation; this is a complex differential equation, the solution of which will enable a physicist to calculate the energy in a system. The hydrogen molecule, which consists of two hydrogen atoms bonded together, is actually the largest system for which Schrödinger's equation can be solved but, in theory, all molecules have a wave function, including the extremely complex aperiodic DNA molecule.

Quantum mechanics tells us that the electrons in atoms have a wave function, although they are normally thought of as particles, and this constitutes the essential weirdness of quantum mechanics: all particles at the quantum level have this wave-particle duality. A physicist who observes a particle will collapse the wave function and find a particle but, if the particle is not specifically observed, it will remain a wave. Schrödinger's wave function is mathematical, but the fact is that what we see all around us in nature also has this wave-particle duality. Light, and indeed all electromagnetic radiation, is an electromagnetic field and this has been quantized, so it also has waveparticle duality. This has profound implications for biological organisms, and indeed it has now been found that photosynthesis - the capturing of a photon by the chlorophyll molecule, whereupon it is delivered to the reaction center in the cell that turns light energy into electrical energy - involves quantum superposition. Electric current is also quantized, which is significant when we consider that the living cell is a complex electrical circuit. So many processes in biology involve ions and other minute particles moving through holes in membranes. The act of observing them will collapse the wave function, and the biologist will see a particle go through a particular hole, but quantum mechanics tells us that, when they are not observed, a multi-particle wave function passes through all the holes.

Quantum mechanics also has manifold applications in electronics, principally because electronics involves nanotechnology that places restrictions on the wave functions of particles, particularly electrons in electric current, which in turn involve another strange feature of quantum mechanics, quantum tunneling. In the 
macroscopic world, if an object does not go through a barrier then the object in its entirety bounces back, but not so in the quantum world. Even though there is a high probability that an electron will not go through a barrier, there remains some probability that it will pass through the barrier nonetheless and appear on the other side.

From these general considerations about the application of quantum mechanics, it will be appreciated that were we to find electron-dense nanostructures in biological organisms, we would enter the world of quantum biology as we would also were we were to find light and radio waves in general playing a large part in biology. In fact, not only are nanostructures ubiquitous in biology but, in the past decade or so, a new field of genetic research known as optogenetics and radiogenetics have emerged and have yielded already tens of thousands of research papers detailing the regulation of genetic processes using light and radio waves. Indeed, brain waves are simply extremely low-frequency (ELF) radio waves, placing us well within the realm of quantum biology.

Before providing specific examples to back up these general statements I return to Erwin Schrödinger, who gave us not only the wave equation that is the core feature of quantum mechanics, but also a quantum theory of genetic mutations [9].

Schrödinger noted the high degree of permanence in hereditary properties. In the case of humans and other animals, the "phenotype," the visible and manifest nature of the individual, is reproduced without appreciable change for generations, across centuries if not millennia - in the case of some species (the crocodile and the tortoise, for example), even millions of years. This stability would be unlikely if mutations involved frequent, small, random variations in the genetic material. Schrödinger then discusses the findings of Dutch botanist Hugo de Vries that in the offspring even of thoroughly pure-bred stocks of barley, a very small number of individuals - two or three in tens of thousands - exhibit small, "jump-like" changes, meaning not that the change is necessarily considerable, but that it represents a discontinuity, an absence of intermediate forms between the original and the new. De Vries called this phenomenon mutation.

This discontinuity is significant, as it is in quantum theory where no intermediate energies occur between two neighboring energy levels. Figuratively, at least, we are discussing the quantum theory of biology, and such mutations are actually due to quantum jumps in the gene molecule. Schrödinger goes on to suggest the actual quantum mechanical processes that could be involved in the mutation of genes as discreet jumps. He attributes the permanence and durability of hereditary material to the fact that the DNA is an organic aperiodic solid (crystal). In inorganic crystals the same structure is repeated over and over, but in an aperiodic crystal every atom, and every group of atoms, plays an individual role, not entirely equivalent to that of all the others. This aperiodicity immensely complicates the wave function for the molecule, as well as the behavior of any forces or energy, such as electricity or phonons, that may be traveling through the crystal. But although aperiodic, the DNA molecule nonetheless has a very precise and fixed structure.

Schrödinger contends that the single event causing a mutation is an ionization (or similar process) occurring within some "critical" volume of the germ cell. He then discusses the fact that the DNA molecule is isomeric and that, as result, the molecule will of necessity have a certain stability: the configuration cannot change, unless at least the energy difference required necessary to "lift" it to the next level is supplied from outside. Thus, this level difference, which is a well-defined quantity, determines quantitatively the degree of stability of the molecule. So a mutation would be caused if part of the molecule received a burst of energy sufficient to cause the electrons to lift to a higher level; this is a purely quantum mechanical process. Further, Schrödinger doesn't mention semi-conductor technology - for the simple reason that was unknown when he was writing - if the DNA molecule is a semi-conductor, such a burst of energy could lift the electrons into the conduction band, which means an electric current would pass through that part of the molecule.

Schrödinger then enters into a discussion of the laws of thermodynamics and concludes it is conceivable that an isomeric change of configuration in some part of the DNA molecule, produced by a chance fluctuation of the vibrational energy, could actually be a sufficiently rare event to be interpreted as a spontaneous mutation. At the time Schrödinger was writing, chance fluctuations in temperature were the only event he could think of that could create a sufficient burst of energy to lift the electrons to a higher level and still be part of the normal processes operating in vivo. At that time, X-ray diffraction was also well known and Schrödinger goes on to discuss X-ray induced mutations where there was a very precise "X-ray coefficient," indicating the percentage of the offspring that will be mutated in a particular way, when a unit dosage of $\mathrm{X}$-ray has been applied to the parents. In other words, mutations induced by X-rays were clearly not random - but nor, of course, were mutations induced by X-rays something that would occur in the living cell under normal conditions.

It has been known since the 1970s that the DNA absorbs and emits light. Biophotons are in the UV to low visible light range, with wavelengths from 200 to $800 \mathrm{~nm}$ [17]. Fritz-Albert Popp, one of the pioneers in biophoton research, found that the DNA molecule will absorb light in the UV frequency and then emit light at different frequencies. He believed the light was being "scrambled" but in fact the UV photons were pushing the electrons within the DNA molecule above the energy threshold for their level and causing them to jump to a higher level. When these electrons then revert to their base or a lower level, they emit light at very precise frequencies according 
to the spectral lines of atoms developed in quantum mechanics. These spectral lines can be UV and visible light [18].

The DNA base-pairs display maximum light absorption at a wavelength of $260 \mathrm{~nm}$ and proteins at $280 \mathrm{~nm}$. It will be noted that these wavelengths are in the nanoscale range, and that they are also in the UV light range- which is to say, this light is not visible. The DNA does absorb light at higher levels, but this is usually caused by light scattering [19]. However, if a DNA molecule is exposed to light in the visible spectrum, it will "get excited and light up." Further, when a DNA molecule is in a "dark state," - its normal condition in the nucleus of a cell in vivo - it will from time to time naturally fluoresce and then revert to its darkened state in which nothing appears to be occurring [20]. However, it is known that plants, specifically onion roots, communicate with each other to induce genetic processes using UV light [21]. It is also well known that large doses of UV light will damage the DNA and cause mutations, but it is quite apparent that even a single photon of UV light emitted from the DNA in one chromosome in the nucleus would be capable of initiating a genetic process in the DNA in another chromosome in the nucleus. UV photons are not visible, so to all intents and purposes the nucleus would appear to be in the "dark state" where nothing is happening. If communication within the nucleus of the cell is mediated via UV light, then the DNA would be capable of initiating mutations in exactly the manner envisaged by Schrödinger.

Thus, there is a quantum theory of mutation in the genetic material involving discrete jumps, one that means that mutations do occur by chance but are not random. According to quantum probability theory, only the mutations with the highest degree of probability will actually occur. However, if quantum biology is at work in our genetic material, determining the frequency and type of mutations, it should be possible to find quantum effects in the structure of the DNA itself and, indeed, throughout all of biology.

The molecular composition of DNA would suggest that it would be a semiconductor. The core DNA base pairs are made up of carbon atoms interspersed with nitrogen, oxygen and hydrogen atoms. Carbon, like silicon, with four electrons in its valence shell is a classical semiconductor, and the nitrogen and hydrogen atoms would act as doping agents. To "dope" a semiconductor makes it conduct electricity more readily. In fact, the doping of carbon nanotubes and composite graphene structures with nitrogen is very common and comparisons have already been drawn with the DNA [22]. The hydrogen atoms play an important role in the doping process, as the hydrogen atom readily donates its sole electron to the nitrogen atoms; this means that, throughout the DNA molecule, the nitrogen atoms are slightly negatively charged, and the hydrogen atoms are slightly positively charged [23]. This, in turn, means that the base-pair components of the DNA double helix themselves present as both a $p$ and an $n$ semiconductor; that is to say, they have both electrons and "holes" that are readily available for conduction. In addition, the DNA double helix has a sugar-phosphate backbone and, since the phosphate groups in the backbone are negatively charged, the DNA is usually surrounded by positive "counterions." The DNA is said to be "ideal for electron transfer" [24].

There has been a great deal of controversy whether the DNA molecule can be considered a metal, or a conducting nanowire, or even a superconductor [24]. Basically, a metal has electrons always available in the conduction band and all that's needed is to apply a voltage and current will flow. With a semiconductor, there is a large gap between the energy levels of the valence band and the conduction band and energy must be applied to the material to make the electrons jump into the conduction band; only then will a current flow if a voltage is applied. A conducting nanowire is a conductor that is only a few nanometers in diameter. A superconductor is a metal with zero resistance which will allow current to flow indefinitely without losing any energy. In fact, levels of resistance have been measured in the DNA which vary widely from one MegaOhm (1 M $\Omega$ ), which indicates that it conducts well, right up to 10 trillion ohms $\left(10^{13} \Omega\right)$ for DNA molecules 40 nanometers or longer, which means that it is an insulator with infinite resistance [24]. Overall, it seems certain that resistance in the DNA increases exponentially with distance and that long DNA molecules are true insulators [24].

The fact is that the semiconducting properties of DNA make it ideal for building nanometer-scale integrated circuits. The DNA molecule is only 2 nanometers in diameter and can be folded into any desired shape. The folded DNA acts as a scaffold to support various nanometer-scale components, such as electrically conductive carbon nanotubes. This process is called DNA origami because it is reminiscent of the ancient Japanese art of paper folding. Rothemund describes this as "like the pegboards people use to organize tools in their garages, only in this case, the pegboard assembles itself from DNA strands and the tools likewise find their own positions" [25]. Similarly, Woolley states that, "We would like to use DNA's very small size, base-pairing capabilities and ability to self-assemble, and direct it to make nanoscale structures that could be used for electronics." According to Woolley, the smallest features on chips currently produced by electronics manufacturers are 14 nanometers wide. That is more than 10 times the diameter of single-stranded DNA, meaning that this genetic material could form the basis for smaller chips. As he notes, however, DNA does not conduct electricity very well, so the solution is to "use the DNA as a scaffold and then assemble other materials on the DNA to form electronics" [36].

In fact, DNA does conduct electricity over longer distances but only if the molecule is immersed in water or in a phosphate buffer solution $[27,28]$. This is actually its natural state in vivo, where the nitrogen elements are hydrophobic, and the sugar-phosphate backbone is 
hydrophilic. The hydrophobic negatively charged nitrogen atoms are what causes the DNA to twist into its characteristic helix shape, thereby preventing water from getting into the middle of the molecule, while the negatively charged sugar-phosphate backbone is actually soluble in water $[29,30]$. It has been found that DNA can only act as a conducting nanowire if it retains its helical structure $[28,31]$. When the DNA is in aqueous solution, the negatively charged sugar phosphate backbone becomes an electron-rich liquid medium that is an excellent conductor of electricity $[32,33]$ This explains reports that DNA acts as a metal for conducting electricity [31]. The nitrogenous base-pairs, being hydrophobic, would continue to act as a semiconductor separately from the metal-like conduction of electricity in the surrounding water, which explains reports that DNA is a conducting nanowire, as well as the fact that it is conducting an alternating current (AC). As noted by Armitage, "This is exactly what you would expect if water is responsible for the conductivity. Water is a polar molecule, across which electrons can shift to produce an alternating current. But they cannot travel freely from molecule to molecule to produce direct current" [33].

A nanowire conducting alternating current (AC) will emit radio waves at the same frequency as the electric current. The DNA in vivo is a transmitter of radio waves and, further, will act as a receiver or antenna, receiving radio waves of whatever frequency whereupon an alternating current of the same frequency will be generated in the nanowire. Additionally, a semi-conducting nanowire can explain how the DNA can intermittently emit UV photons to communicate with itself in other chromosomes in the nucleus, as there would be electrons dropping back from the conduction band into their "holes" in the valence band, thus emitting UV as well as visible light.

A recent study notes some curious facts about the electromagnetic properties of DNA [34]. For example, link DNA is said to "zig-zag" back and forth between "stacks" of these mini-coils, while the histone cores of the mini-coils are reported to link with each other. There is said to be a "permanent dipole moment" between each mini-coil that generates "electric dipolar oscillation" between them. The capacity for mutual induction of electromotive force (emf) in the nucleosomal fiber would be virtually infinite. In addition, the current that has been detected in the nucleosomal fiber is "oscillating;" that is to say, it is an alternating current with frequencies between 2 and $50 \mathrm{MHz}$. The frequencies are said to vary from region to region in the chromatin depending on the "DNA-protein complexes in that region." As this is essentially an alternating current, it is suggested that the mere fact of the DNA synthesizing the superparamagnetic histone core, coiling itself around the core, and then all these coils "clustering" into "stacks" in the nucleosomal fiber, would be sufficient to generate a self-perpetuating current. [34]

Another curious item that emerges from the same study is that when the chromatin is not in M-phase - that is, when the chromosomes are not tightly compacted for the purpose of cell division - the chromosomes appear to relax or unwind in the nucleus; it is during this phase that the non-coding sections of the DNA (the "junk DNA") adopt the quaint custom of "chromosome kissing," whereby these "introns" on several different chromosomes will be seen to approach each other based on their oscillating natural frequencies. What sort of electrical forces and emf are being generated during these chromosome kissing sessions is anybody's guess. Given, however, the electromagnetic complexity of nucleosomal fiber it is possible that the forces would be significant. At the very least, the mere proximity to each other of several chromosomes with their respective potent "junk" electromagnetic fields would be sufficient to generate a current. Interestingly, epigenetic features appear to be involved here as well.[34]

More than 20 years ago, Roger Penrose found quantum effects in the microtubules in neurons and surmised that this had something to do with generating consciousness. Neurons, like all living cells, emit light as they work. Neurons contain many light-sensitive molecules, including porphyrin rings, flavin rings, pyridinic rings, lipid chromophores and aromatic amino acids. In particular, mitochondria - the structures inside cells that produce energy - contain several prominent chromophores. The presence of these light-sensitive molecules suggests that they might be influenced by biophotons originating in the DNA. A study suggests that microtubules can act as wave guides, channeling light from one part of a cell to another [35]. In other words, they act as optical fiber, channeling light signals to all the cells in the brain. It is known that electrical signals are too slow to do this effectively; light signals, however, could instantaneously coordinate electrical activity in different parts of the brain - that is to say, trigger action potentials in neurons in diverse regions. Using light to trigger action potentials in neurons is how optogenetics started, and there are now thousands of research papers on genes and other structures in the cell being activated by light as well as radio waves of lower frequencies.

The fact is that these microtubules are ubiquitous in living cells, even plant cells. Microtubules are actually nanotubes; it is a moot point whether they act as a semi-conductor of electricity, but they do have positive and negative ends, which creates an electromagnetic field within them [36]. Microtubules are the internal scaffolding inside cells, providing structural support but also creating channels along which negatively charged proteins move on account of the electromagnetic field. Another feature ubiquitous to living cells is microfilaments, which are actually nanowires that conduct electricity [37]. There are many other electron-dense nanostructures in the brain [38]; the living cell is a complex electronic circuit, and there are quantum effects everywhere one looks in biology. 


\section{Conclusions}

The original intent of this paper was to critique Neo-Darwinism by focusing on the different proteins in related species. For instance, our closest relative, genetically speaking, is the chimpanzee; precise DNA sequencing has found only $1-2 \%$ difference between humans and chimpanzees at the genetic level [39]. Yet $80 \%$ of human proteins are different from those that make up the phenotype of the chimpanzee [39]. We are told that humans split from their closest African ape relatives in the genus Pan six to seven million years ago, so orthodox theory would maintain that natural selection of random mutations in the genome over seven million years in humans and chimpanzees has resulted in this $1-2 \%$ difference in DNA, and the profound difference in phenotypes (both physical and mental) and proteins.

To questions of how a particular facet of a phenotype of a species can occur through natural selection of random genetic mutations, the orthodox Neo-Darwinian response amounts to little more than "Well, that's just the way it is." A valid scientific theory, however, must set out the conditions under which it can be proved wrong. It has been observed by others that Neo-Darwinism shares with pseudoscience the feature of being unfalsifiable.

It is suggested here that the proof or disproof resides in this issue of the difference of proteins between species not only for Neo-Darwinism, but also for Schrödinger's theory that mutations occur in quantum leaps. Admittedly that study in 2005 was done on just 127 proteins, which found that only $20 \%$ of the amino acids are in the same position, but there is surely the need here for a follow-up study to see if the differences in the DNA and the proteins are correlated. If the $1-2 \%$ difference in the DNA sequences of humans and chimpanzees, for example, does not actually comprise $80 \%$ of the genes that code for proteins in both humans and chimps, the whole idea that evolution occurs through genetic mutations, whether random or quantum jumps, is called into question. The theory here presented about the evolution of consciousness, on the other hand, can explain the extraordinary diversity of phenotypes through the simple, if heterodox, premise that there is a teleological aspect to evolution; that, for the past 3.8 billion years there has been an evolution of consciousness; and that it is this intelligence, which is in the DNA itself, that has masterminded or designed its own evolution.

\section{REFERENCES}

[1] Coghlan, A. (2018) Our Ancestors mated with the mystery 'Denosovian' people - twice, New Scientist, March 15, 2018.

[2] Maxmen, A. (2018) 'Dark matter' DNA influences brain development, Nature News, January 18, 2018.

[3] Pennisi, E. (2004) Searching for the genome's second code. Science 306:632-635.

[4] Darwin, C. (1872) On The Origin of Species, or the Preservation of Favored Races in the Struggle for Life, 6th Edition, London: John Murray.

[5] Horstman, L.L. (2005) Evolution Fact \& Fantasy: The Psychogenic Theory, Booksurge. Kindle Edition.

[6] Haldane, J.B.S. (1929). The origin of life. The Rationalist Annual. 148: 3-10.

[7] Dawkins, R. The Blind Watchmaker: Why the Evidence of Evolution Reveals a Universe without Design. W. W. Norton \& Company. Kindle Edition.

[8] Bartholomew, B.Y. (2017) A Review of psi activity in the DNA, Universal Journal of Psychology, 5(1): 22-29.

[9] Schrödinger, E. (1956) What is Life? (Canto) Cambridge University Press. Kindle Edition.

[10] Nishan Shettigar, N., Joshi1, A., Dalmeida, R., Gopalkrishna1, R., Anirudh Chakravarthy, A., \& Patnaik, S. (2017) Hierarchies in light sensing and dynamic interactions between ocular and extraocular sensory networks in a flatworm, Science Advances, 3(7).

[11] Bartholomew, B.Y. (2017) Our Unconscious Soul: A re-look at Aristotle Descartes \& The Upanishads, Universal Journal of Psychology, 5(6): 272-282.

[12] Jouvet, M. (1992) Le sommeil et le rêve [The sleep and the dream]. Paris: Odile Jacob.

[13] Vadat, S., Fogel, S., Benali, H., \& Doyon, J. (2017) Network-wide reorganization of procedural memory during NREM sleep revealed by fMRI, eLife; 6:e24987.

[14] Macchi M, Bruce J (2004). Human pineal physiology and functional significance of melatonin. Frontiers of Neuroendocrinology. 25 (3-4): 177-95.

[15] Youngson, R.M. (2004) Putamen Collins Dictionary of Medicine.

[16] James, W. (1982) Varieties of Religious Experience, Penguin American Library.

[17] Popp, F. (2003). Properties of biophotons and their theoretical implications. Indian Journal of Experimental Biology. 41 (5): 391-402.

[18] Rattemeyer, M., Popp, F. A., and Nagl, W. Evidence of Photon Emission from DNA in Living Systems. Naturwissen 68 (1981): 572-80.

[19] Stulnig T.M. \& Amberger A. (1994) Exposing contaminating phenol in nucleic acid preparations, Biotechniques, 16(3).

[20] Dong, B., Almassalha, L.M., Stypula-Cyrus, Y., Urban, B.E., Chandler, J.E., Nguyen, T-Q., Sun, C., Zhang, H.F. \& Backman, V. (2016) Superresolution intrinsic fluorescence imaging of chromatin utilizing native, unmodified nucleic acids for contrast, Proceedings of the National Academy of Sciences of the United States of America, 113(35).

[21] Sun, Y., Wanga, C., \& Dai, J. (2010) Biophotons as neural 
communication signals demonstrated by in situ biophoton autography, Photochemical \& Photobiological Sciences, 3.

[22] Won, J. L., Uday, N. M., Ju, M. L., Joonwon, L., Tae, H. H., and Sang, O. K. (2014) Nitrogen-Doped Carbon Nanotubes and Graphene Composite Structures for Energy and Catalytic Applications, Chemical Communications, 50: 6818-30.

[23] Gerrard, P. and Malcolm, R. (2007) Mechanisms of Modafinil: A Review of Current Research. Journal of Neuropsychiatric Disease and Treatment, 3(3): 349-64.

[24] Dekker, C. and Ratner M. A. (2001) Electronic Properties of DNA. Physics World.

[25] Science Daily (2016). $<$ https://www.sciencedaily.com/relea ses/2016/07/16071213 3919.htm>.

[26] Science Daily (2016)<https://www.sciencedaily.com/releas es/2016/03/16031408 4824.htm>.

[27] Armitage, N. P., Briman, M., and Gruner, G. (2003) Charge Transfer and Charge Transport on the Double Helix, Physica Status Solidi, 69.

[28] Slinker, D. J., Muren, N. B., Renfrew, S. E., and Barton, J. K. (2011) DNA Charge Transport over $34 \mathrm{~nm}$, Nature Chemistry, 3: 228-33.

[29] Zhao, X. (2011) Self-assembly of DNA Segments on Graphene and Carbon Nanotube Arrays in Aqueous Solution: A Molecular Simulation Study, Journal of Physical Chemistry, 14: 6181-9.

[30] Westhof, E. (1993) Structural Water Bridges in Nucleic Acids. Water and Biological Macromolecules. London: Macmillan Education: 226-43.

[31] Brown, M. (2011) Electrons Charge down DNA Molecular Wire, Chemistry World, Royal Society of Chemistry.
$<$ http://www.rsc.org/chemistryworld/News/2011/January/3 0011102.asp>.

[32] Turro, N. J., Barton, J. K., and Tomalia, T. A. (1991) Molecular Recognition and Chemistry in Restricted Reaction Spaces. Photophysics and Photoinduced Electron Transfer on the Surfaces of Micelles, Dendrimers, and DNA. Accounts of Chemical Research, 24(11): 332-40.

[33] Biever, C. (2003) DNA - Celebrating 50 Years of the Double Helix, New Scientist, March 15, 2003.

[34] Zhao, Y., \& Zhan, Q. (2012) Electric oscillation and coupling of chromatin regulate chromosome packaging and transcription in eukaryotic cells, Theoretical Biology and Medical Modeling, 9(27).

[35] Rahnama, M., Bokkon, I., Tuszynski, J., Cifra, M., Sardar, P., \& Salari, V. (2010) Emission of Mitochondrial Biophotons and their Effect on Electrical Activity of Membrane via Microtubules, Journal of Integrative Neuroscience, 10(1).

[36] Kim, T., Kao, M.T., Hasselbrink, E.F., Meyhöfer, E. (2007) Active alignment of microtubules with electric fields, Nano Letters, 7(1)

[37] Lovely, D. (2018) Many More Bacteria Have Electrically Conducting Filaments, UMassAmerherst News \& Media Relations, $<\mathrm{http}$ //www.umass.edu/newsoffice/article/many-more-bact eria-have-electrically>

[38] Smythies, J., \& Edelstein, L. (2013) Telocytes, exosomes, gap junctions and the cytoskeleton: the makings of a primitive nervous system?, Frontiers in Cellular Neuroscience, 7:278.

[39] Glazko G., Veeramachaneni V., Nei M., \& Makałowski W. (2005) Eighty percent of proteins are different between humans and chimpanzees, Gene, 346:215-9 